\title{
PROGNOSIS OF BREAST CANCER IN VERY YOUNG AGE (LESS THAN 30 YEARS)
}

Razia Bano ${ }^{1,2}$, Mariam Salim², Mahwish Abid², Akif Zaidi², Amina Iqbal Khan²

${ }^{1}$ Breast Clinic, Combined Military Hospital, Rawalpindi, Pakistan, ${ }^{2}$ Department of Surgical Oncology, Shaukat Khanum Memorial Cancer Hospital and Research Centre Lahore, Pakistan

Received: 28 September 2015 / Accepted: 31 March 2016

\begin{abstract}
Purpose: Breast cancer diagnosed at a younger age has aggressive biology being triple negative and high grade and is associated with poor prognosis.

Materials and Methods: Retrospectively data of 121 patients age 30 years or younger registered during the year 2008 were reviewed. Data were extracted from the cancer registry department of the institute. Demographics studied were the age at diagnosis, gender, pregnancy or lactation association, family history of breast cancer, histopathological diagnosis, and stage of the disease, receptors, type of treatment, response, local recurrence, distant relapse, and survival.
\end{abstract}

Results: A total of 121 patients with age 30 years or less were included. An only a single patient was male. The age range was from 20 to 30 years; bilateral involvement was seen in a single patient. Almost half $50.4 \%(n=61)$ patients had locally advanced disease at presentation. Pregnancy/lactation-associated breast cancer was seen in $29.8 \%$ $(n=36)$. The most common stage was Stage III (52.1\%) and Stage II (33.9\%). Invasive ductal carcinoma was the most common histology $94.2 \%(n=114)$ of patients; triple negative was the most common molecular subtype present in $46.3 \%(n=56)$. Chemotherapy was received by $92.6 \%(n=112), 88.4 \%(n=107)$ patients received radiation therapy. Modified radical mastectomy was performed in $57 \%(n=69)$, breast conservation surgery in $35.5 \%(n=43)$, followup period was 5 years, local recurrence was observed in $12.4 \%(n=15)$ and cancer related deaths were $42.1 \%(n=51)$.

Conclusions: Breast cancer in very young has very aggressive tumour biology, needs aggressive treatment with surgery, chemotherapy, radiation therapy and hormonal therapy.

Key words: Breast cancer, pregnancy-associated aggressive tumour biology, triplenegative, young

\section{Introduction}

Breast cancer is the most common type of cancer found in the female population. Breast cancer in young age is relatively uncommon accounting for $7 \%$ in women diagnosed at 40 years or younger. ${ }^{[1]}$ Young age $(<35)$ is an independent risk factor for breast cancer-related deaths, they are at higher risk of death as compared to middle age women. ${ }^{[2]}$ Multiple studies from different centres and different countries show that breast cancer in young females presents as an aggressive disease which is difficult to manage and shows poor outcome in terms of survival when they are compared with the older patients..$^{[3,4]}$ Younger patients $<35$ years, even with receptors positive

Correspondence: Dr. Razia Bano, Breast Clinic, Combined Military Hospital, Rawalpindi, Pakistan.

Email: raazia240@gmail.com have 1.5 -fold higher risks for mortality as compared to those above $35 .{ }^{[5]}$ Tumours in young females are usually node positive, locally advance with negative hormonal status. The reason for this unusual behaviour is yet to be found. ${ }^{[6,7]}$

Our aim was to review the demographics, to see the incidence of brain metastasis, after complete treatment, and prognosis of breast cancer in very young females.

\section{Materials and Methods}

A total of 179 patients age 30 years or less were registered at our institute from January 2008 to December 2008, after exclusion of patients with incomplete data final sample size was 121. Medical records were reviewed for clinicians notes, medical reports, and treatment charts. Demographics studied were the age at diagnosis, gender, 
clinical presentation, pregnancy or lactation associated, family history of breast cancer in a first-degree relative and locally advanced disease (tumour size $>5 \mathrm{~cm}$, nipple retraction, skin involvement, inflammatory features) histopathological diagnosis, stage of the disease, receptors, type of treatment, response to neoadjuvant chemotherapy, local recurrence, distant relapse, disease-free and overall survival (OS). Patients were categorised into luminal subgroups according to the receptors (oestrogen receptor, progesterone receptor and her-2 neu receptor). Diseasefree survival was calculated from the date of complete treatment till the locoregional recurrence, while OS was calculated from the date of diagnosis till the time to death. Neoadjuvant chemotherapy was offered to all patients with locally advanced disease, lymph node-positive disease and Stage IV disease, response to neoadjuvant chemotherapy was assessed clinically, radiological, pathologically as complete response (CR), partial response (PR) or no response (NR). 5 years survival was calculated using Kaplan-Meier survival curve. Data were analysed using SPSS version 19.

\section{Results}

The final sample size was 121 ; the age range was 20 years -30 years with a median age of 28 years. Demographic characteristics are summarised in Table 1. Female patients were $99.1 \%(n=120)$; only a single patient was male. Locally advanced disease (tumour size $>5 \mathrm{~cm}$, skin involvement and clinically lymph nodes node-positive disease) was present in 50.4\% $(n=61)$ patients, $76.8 \%(n=93)$ patients had nodal metastasis at presentation while $28(23.1 \%)$ of patients were node negative, pregnancy/lactation-associated breast cancer was found in $29.8 \%(n=36)$. Left side involvement was seen in $53.7 \%(n=65)$; only a single patient had bilateral disease at the time of presentation. Most patients presented in Stages III and II disease, $52.1 \%(n=63)$ and $33.9 \%$ $(n=41)$, respectively, $10 \%(n=13)$ of patients presented with Stage IV disease. Most common histological subtype was invasive ductal carcinoma, found in $94.2 \%(n=114)$, other less common types were mucinous, invasive lobular, malignant phyllodes and ductal carcinoma in situ. Triple negative was the most common luminal subtype present in $46.3 \% \%(n=56)$, followed by luminal A $29.8 \%(n=36)$ and luminal B $16.5 \%(n=20)$, her-2 neu overexpression was seen in $7.4 \%(n=9)$ patients.
Table 1: Demographic characteristics

\begin{tabular}{|c|c|}
\hline Characteristics & Frequency \% (n) \\
\hline \multicolumn{2}{|l|}{ Age group } \\
\hline $20-25$ years & $18.1(22)$ \\
\hline $26-30$ years & $81.8(99)$ \\
\hline \multicolumn{2}{|l|}{ Gender } \\
\hline Females & $99.1(120)$ \\
\hline Male & $0.8(1)$ \\
\hline \multicolumn{2}{|l|}{ Locally advanced } \\
\hline Yes & $50.4(61)$ \\
\hline No & $49.6(60)$ \\
\hline \multicolumn{2}{|l|}{ Pregnancy/lactation associated } \\
\hline Yes & $29.8(36)$ \\
\hline No & $70.2(85)$ \\
\hline \multicolumn{2}{|l|}{ Family history } \\
\hline Present & $11.6(14)$ \\
\hline Absent & $88.4(107)$ \\
\hline \multicolumn{2}{|l|}{ Histology } \\
\hline Invasive ductal carcinoma & $94.2(114)$ \\
\hline Mucinous carcinoma & $2.47(3)$ \\
\hline Malignant haloids & $0.8(1)$ \\
\hline Invasive lobular carcinoma & $1.65(2)$ \\
\hline Ductal carcinoma in situ & $0.8(1)$ \\
\hline \multicolumn{2}{|l|}{ Molecular subtypes } \\
\hline Luminal A & $29.8(36)$ \\
\hline Luminal B & $16.5(20)$ \\
\hline Triple negative & $46.3(56)$ \\
\hline Her 2 neu type & $7.4(9)$ \\
\hline \multicolumn{2}{|l|}{ Stage } \\
\hline Stage 0 & $3.3(4)$ \\
\hline Stage I & $0.8(1)$ \\
\hline Stage II & $33.9(41)$ \\
\hline Stage III & $52.1(63)$ \\
\hline Stage IV & $9.1(11)$ \\
\hline
\end{tabular}

Almost half of the patients $49.6 \%(n=60)$ received neoadjuvant chemotherapy. CR was observed in $20 \%(n=12)$ while $66.6 \%(n=40)$ had PR and 5 patients showed NR to first-line chemotherapy.

Modified radical mastectomy was performed in 57\% $(n=69)$, while $35.5 \%(n=43)$ underwent breast conservation surgery, nine patients were not candidates for surgery as they had progressive Stage IV disease. 52 patients received chemotherapy in the adjuvant setting. Most of our patients $88.4 \%(n=107)$ did receive radiation 
therapy. Hormonal treatment in the form of tamoxifen was received by $45.5 \%(n=55)$ of patients, targeted therapy in the form of trastuzumab was received by four patients only [Table 2]. Local relapse occurred in $12.4 \%$ $(n=15)$, while $33.8 \%(n=41)$ developed distant relapse, $17.4 \%(n=21)$ patients developed brain metastasis. After 5 years only $57.9 \%(n=70)$ were alive, cancer related deaths were $42.1 \%(n=51) .5$ years OS was $57.9 \%$. 5 years survival according to the stage at presentation is shown in Figure 1.

\section{Discussion}

Breast cancer in women of age 35 is different from breast cancer occurring at an older age ( $>40$ years), it has aggressive tumour biology, high proliferative index, higher tumour grade, lack of oestrogen receptors and progesterone positivity, usually are poorly differentiated and carry poorer survival as compared to the older population. ${ }^{[9]}$ Most of our patients had invasive ductal carcinoma grade two or three, $46.3 \%$ of our patients were triple negative.

\section{Table 2: Treatment details}

\begin{tabular}{l|c}
\hline Chemotherapy & Frequency \% (n) \\
\hline Neoadjuvant & $49.6(60)$ \\
\hline Adjuvant & $42.1(52)$ \\
\hline Surgery & $57(69)$ \\
\hline Modified radical mastectomy & $35.5(43)$ \\
\hline Breast conservation surgery & $7.4(9)$ \\
\hline No surgery & \\
\hline Radiation to breast & $88.4(107)$ \\
\hline Received & $11.6(14)$ \\
\hline Not received & \\
\hline Hormonal Treatment & $45.5(55)$ \\
\hline Received & $54.5(66)$ \\
\hline Not received & $3.3(4)$ \\
\hline Targeted therapy (herceptin) & \\
\hline Locoregional recurrence & $12.4(15)$ \\
\hline Yes & $87.6(106)$ \\
\hline No & $33.8(41)$ \\
\hline Distant relapse & $17.4(21)$ \\
\hline Brain mets & \\
\hline Outcome & $57.9(70)$ \\
\hline Alive & $42.1(51)$ \\
\hline Dead &
\end{tabular}

Due to the lack of screening programs in the developing countries presentation is often delayed, ${ }^{[10]}$ almost half of our patients $(50.4 \%)$ were locally advanced at presentation. Due to unfavourable tumour biology younger women has low survival as compared to the elderly. ${ }^{[11]} 5$ years OS in our study population was $57.9 \%$.

The mean age at diagnosis is much younger in Asian countries as compared to western; the incidence is increasing with the passage of time. ${ }^{[12]}$ Pregnancyassociated breast cancer (PABC) is defined as breast cancer arising in pregnant women or lactation, 1 year after the delivery, ${ }^{[13]}$ it carries poorer prognosis due to delay in diagnosis as breast size increase and denser. PABC is very aggressive with her- 2 neu overexpression, or triple negative with higher proliferative index. ${ }^{[14]}$ The interactions between pregnancy and breast cancer are complex and variable, may be increased hormonal levels promote proliferation of existing tumours, ${ }^{[15]} 29.8 \%$ of our patients presented with pregnancy or lactation-associated breast cancer, all presented with larger tumour size. Risk of breast cancer becomes 2 times in patients with family history of breast cancer, however, for PABC, the risk remains the same as for non $\mathrm{PABC}$ tumours according to Johansson et al. ${ }^{[16]} 11.6 \%$ of our patients have a positive family history of first-degree relative.

Triple negative breast cancer is an independent poor prognostic factor, this molecular subtype is more common

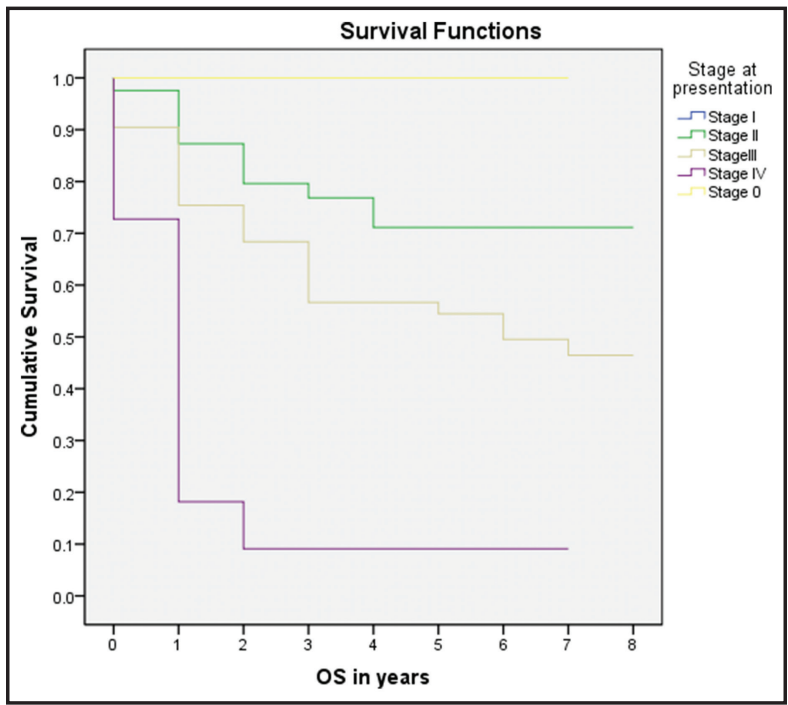

Figure 1: Kaplan-Meier showing 5 years overall survival according to stage 
in the younger age group, therefore, two worst things combine together, risk of death becomes 2.7-folds when triple negative cancer arise in younger population, ${ }^{[17]}$ $46.3 \%$ of our patients were triple negative and only nine patients showed her-2 neu overexpression. Tang et al. carried out a retrospective review of 1360 Chinese women $<40$ years of age and studied the relationship between luminal B subtype and prognosis; they found increased risk of local recurrence and increase death risk in these patients. ${ }^{[18]}$ Younger patients also show a higher proportion of BRCA1 and BRCA 2 mutations. ${ }^{[19]}$

Chemotherapy is the mainstay of treatment in invasive breast cancer, to achieve local as well as systemic control, inpatient with locally advanced disease, lymph node-positive patients and to downstage tumour size in patients who are candidates for breast conservation. ${ }^{[20]}$ Women who are $<30$ years who do not receive chemotherapy are at high risk of local and distant relapse. 60 patients in our study received neoadjuvant chemotherapy while 52 patients received chemotherapy after surgery.

Nearly $57 \%$ of our patients underwent modified radical mastectomy, while $35.5 \%$ underwent breast conservation surgery, Cao et al. compared local recurrence and survival rate in younger patients undergoing breast conservation or mastectomy and they observed that mastectomy offers no additional survival benefits compared to breast conservation. ${ }^{[21]}$ According to Bleyer et al. younger women carries poorer survival in all stages of the disease when compared to older women, ${ }^{[22]}$ they compared women age groups; 20-35 and 45-75 years old and for all the stages younger patients had decreased OS as compared to older patients.

Many studies have shown that age itself is a risk factor for poor prognosis, Brandit et al. studied age at diagnosis in relation to the survival in 4453 women of different age groups and observed that after follow-up period of 10 years women of age group $<40$ years with axillary lymph node-negative disease had poorer outcome. ${ }^{[23]} \mathrm{We}$ also found a higher mortality rate in our population despite aggressive treatment. Andres et al. concluded that younger age at the time of diagnosis carries poorer prognosis. ${ }^{[24]}$ Assi et al. described breast cancer in younger age as very aggressive tumours with poor prognostic factors and higher recurrence rate and distant relapse leading to worst prognosis. ${ }^{[25]}$

\section{Conclusions}

The incidence of breast cancer in very young females $(<30)$ is increasing over the years, tumour biology in this age group is aggressive, with poorer prognostic factors. Since half of our patients presented with advanced stage; therefore, we emphasize the need to increase awareness among the younger population to achieve better disease control.

\section{Acknowledgments}

The authors would like to thank Dr. M. Zulqarnain Chaudhry and Huma Majeed Khan provided useful input as treating clinicians and also thank Dr. Saima Riaz performed statistical analysis on the data.

\section{Conflict of Interest}

The authors declare that they have no conflict of interest.

\section{References}

1. Gelmon $\mathrm{K}$, Partridge AH, Morrow M, et al. ASCO Educational Book 2005. Breast Cancer in Young Women: Epidemiology, Treatment, and Survivorship Issues. Alexandria, VA: American Society of Clinical Oncology; 2005. p. 61-7.

2. Fredholm H, Eaker S, Frisell J, et al. Breast cancer in young women: Poor survival despite intensive treatment. PLoS One 2009;4:e7695.

3. Kroman N, Jensen MB, Wohlfahrt J, et al. Factors influencing the effect of age on prognosis in breast cancer: Population based study. BMJ 2000;320:474-8.

4. Xiong Q, Valero V, Kau V, et al. Female patients with breast carcinoma age 30 years and younger have a poor prognosis: The M.D. Anderson cancer center experience. Cancer 2001;92:2523-8.

5. Han W, Kang SY, Korean Breast Cancer Society. Relationship between age at diagnosis and outcome of premenopausal breast cancer: Age less than 35 years is a reasonable cut-off for defining young age-onset breast cancer. Breast Cancer Res Treat 2010;119:193-200.

6. Albain KS, Allred DC, Clark GM. Breast cancer outcome and predictors of outcome: Are there age differentials? J Natl Cancer Inst Monogr 1994;16:35-42.

7. Remvikos Y, Magdelenat H, Dutrillaux B. Genetic evolution of breast cancers. III: Age-dependent variations in the correlations between biological indicators of prognosis. Breast Cancer Res Treat 1995;34:25-33. 
8. Brinton LA, Sherman ME, Carreon JD, et al. Recent trends in breast cancer among younger women in the United States. J Natl Cancer Inst 2008;100:1643-8.

9. Walker RA, Lees E, Webb MB, et al. Breast carcinomas occurring in young women ( $<35$ years) are different. Br J Cancer 1996;74:1796-800.

10. Akarolo-Anthony SN, Ogundiran TO, Adebamowo CA. Emerging breast cancer epidemic: Evidence from Africa. Breast Cancer Res 2010;12 Suppl 4:S8.

11. Azim HA Jr., Michiels S, Bedard PL, et al. Elucidating prognosis and biology of breast cancer arising in young women using gene expression profiling. Clin Cancer Res 2012; 18:1341-51.

12. Ministry of Health and Welfare. Annual Report of Cancer Statistics in Korea in 2011. Korea: Goyang Korea Central Cancer Registry; 2012.

13. Meshikhes AW, Al-Mubarek MA, Al-Tufaif AA. Breast cancer during pregnancy and lactation. Saudi Med J 2004; 25:531-2.

14. Asgeirsson KS. Pregnancy-associated breast cancer. Acta Obstet Gynecol Scand 2011;90:158-66.

15. Albrektsen G, Heuch I, Thoresen S, et al. Clinical stage of breast cancer by parity, age at birth, and time since birth: A progressive effect of pregnancy hormones? Cancer Epidemiol Biomark Prev 2006;15:65-9.

16. Johansson AL, Andersson TM, Hsieh CC, et al. Family history and risk of pregnancy-associated breast cancer (PABC). Breast Cancer Res Treat 2015;151:209-17.
17. Keegan TH, Press DJ, Tao L, et al. Impact of breast cancer subtypes on 3-year survival among adolescent and young adult women. Breast Cancer Res 2013;15:R95.

18. Tang LC, Jin X, Yang HY, et al. Luminal B subtype: A key factor for the worse prognosis of young breast cancer patients in China. BMC Cancer 2015;15:201.

19. Bayraktar S, Amendola L, Gutierrez-Barrera AM, et al. Clinicopathologic characteristics of breast cancer in BRCAcarriers and non-carriers in women 35 years of age or less. Breast 2014;23:770-4.

20. Zaharia M, Gómez H. Neoadjuvant chemotherapy in the treatment of locally advanced breast cancer. Rev Peru Med Exp Salud Publica 2013;30:73-8.

21. CaoJQ, OlsonRA,TyldesleySK.Comparison of recurrenceand survival rates after breast-conserving therapy and mastectomy in young women with breast cancer. Curr Oncol 2013; 20:e593-601.

22. Bleyer A, Barr R, Hayes-Lattin B, et al. The distinctive biology of cancer in adolescents and young adults. Nat Rev Cancer 2008;8:288-98.

23. Brandt J, Garne JP, Tengrup I, et al. Age at diagnosis in relation to survival following breast cancer: A cohort study. World J Surg Oncol 2015;13:33.

24. Anders CK, Johnson R, Litton J, et al. Breast cancer before age 40 years. Semin Oncol 2009;36:237-49.

25. Assi HA, Khoury KE, Dbouk H, et al. Epidemiology and prognosis of breast cancer in young women. JThorac Dis 2013; 5 Suppl 1:S2-8. 